\title{
A correção da produção escrita no Caderno Saberes e Aprendizagens do município de São Paulo sob o olhar da autoria e da subjetividade
}

\author{
Júlio César de Carvalho Santos ${ }^{1}$ \\ Vanessa Stochi Lucri²
}

\section{RESUMO}

Este trabalho é o resultado de uma pesquisa sobre as motivações e análises de autoria e subjetividade presentes nas grades de correção de produção textual oferecidas no Caderno de Saberes e Aprendizagens de Língua Portuguesa da Cidade de São Paulo - Volume 1, distribuído em 2018. A pesquisa foi motivada a partir do seguinte questionamento: estaria essa referência de correção permitindo que o professor avalie o texto dos alunos partindo desses dois conceitos mencionados autoria e subjetividade? O objetivo deste estudo foi verificar como os procedimentos de correção avaliam as questões de autoria dos alunos. Para tanto, utilizaremos como fundamento teórico as propostas de análise mencionadas no Currículo da Cidade, por meio do eixo práticas de produção de texto escrito e as considerações de subjetividade da escrita. Para realizar este trabalho foi utilizado um corpus composto de correções de minicontos elaborados por alunos pertencentes ao chamado Ciclo Autoral, a partir da grade de correção proposta pelo Caderno da Cidade. Os resultados apontam que determinada grade dá margem a respostas avaliativas dicotômicas por parte do professor, como "sim" ou "não", e não colaboram para que o processo de correção permita ao professor observar as marcas de subjetividade do aluno. Conclui-se que tal questionamento do material não destaque uma avaliação aprofundada da subjetividade e autoria do aluno, abrangendo uma parte superficial dos indícios de autoria e uma conceitualização

1 Mestre em Linguística Aplicada pela Universidade de Taubaté - Unitau. Doutorando em Educação pela Faculdade de Educação da USP. Professor de Língua Portuguesa da rede municipal de ensino da Cidade de São Paulo. https://orcid.org/0000-0002-3372-1643. E-mail: jucercarvalho@usp.br

2 Mestranda do Programa de Pós-Graduação em Educação, na Universidade de São Paulo. Professora de Ensino Fundamental II e Médio da Prefeitura Municipal de São Paulo. E-mail:vanessa.lucri@usp.br 
vaga do que seria subjetividade, podendo trazer um olhar pouco reflexivo no processo de correção.

Palavras-chave: Currículo. Redação. Autoria. Subjetividade.

\section{The correction of written production in the "Caderno Saberes e Aprendizagens" of the city of São Paulo under the perspective of authorship and subjectivity}

\section{ABSTRACT}

This work is the result of a research on the motivations and analysis of authorship and subjectivity which are part of the text production correction sheet offered in the "Notebook of Knowledge and Learning of Portuguese Language of the City of São Paulo - Volum 1", distributed in 2018. The research was motivated from the following question: would be this method of correction allowing the teacher to evaluate the students' texts from these two mentioned concepts - authorship and subjectivity? The aim of this study was to check how the correction procedures evaluate the questions written by the students. For this analysis, we are going to use, as theoretical basis, the proposals of analysis mentioned in the curriculum of the city throughout the focus on written text production practices and the subjectivity considerations to the writing. To accomplish this work, a corpus made of corrections of short stories elaborated by students from Authoral Circle was used, from the correction sheet presented by the Caderno da Cidade (city brochure). The results show that determined sheet correction gives room to dichotomous evaluatives answers by the teacher, such as "yes" or "no", and do not help in order to the correction process allows to the teacher see the subjectivity marks of the student. It is concluded that such questioning of the subject does not highlight a deep evaluation of the student subjectivity and authorship, embracing a superficial part of the evidences of authorship and a vague conception of what subjectivity would be, and it can reveal a poor reflexive view of the correction process.

Keywords: Curriculum. Essay. Authorship. Subjectivity. 


\section{La corrección de la producción escrita en el Cuaderno Saberes y aprendizajes del municipio de São Paulo bajo la mirada de la autoría y de la subjetividad}

\section{RESUMÉN}

Este trabalho é o resultado de uma pesquisa sobre as motivações e análises de autoria e subjetividade presentes nas grades de correção de produção textual oferecidas no Caderno de Saberes e Aprendizagens de Língua Portuguesa da Cidade de São Paulo - Volume 1, distribuído em 2018. A pesquisa foi motivada a partir do seguinte questionamento: estaria essa referência de correção permitindo que o professor avalie o texto dos alunos partindo desses dois conceitos mencionados autoria e subjetividade? O objetivo deste estudo foi verificar como os procedimentos de correção avaliam as questões de autoria dos alunos. Para tanto, utilizaremos como fundamento teórico as propostas de análise mencionadas no Currículo da Cidade, por meio do eixo práticas de produção de texto escrito e as considerações de subjetividade da escrita. Para realizar este trabalho foi utilizado um corpus composto de correções de minicontos elaborados por alunos pertencentes ao chamado Ciclo Autoral, a partir da grade de correção proposta pelo Caderno da Cidade. Os resultados apontam que determinada grade dá margem a respostas avaliativas dicotômicas por parte do professor, como "sim" ou "não", e não colaboram para que o processo de correção permita ao professor observar as marcas de subjetividade do aluno. Conclui-se que tal questionamento do material não destaque uma avaliação aprofundada da subjetividade e autoria do aluno, abrangendo uma parte superficial dos indícios de autoria e uma conceitualização vaga do que seria subjetividade, podendo trazer um olhar pouco reflexivo no processo de correção.

Palavras clave: Plan de estudios. Escritura. Autoría. Subjetividad.

\section{Introdução}

Os professores de língua materna são expostos ao desafio de ensinar escrita em todas as séries do ensino regular no Brasil. Embora o ato de ensinar a escrever seja imprescindível, considera-se um grande desa- 
fio para o professor, já que em sua formação acadêmica, os docentes não são preparados para tal, assim, como mencionado por Hillocks (2006, p.50, tradução nossa): " [...] as faculdades e universidades simplesmente não preparam os professores para o ensino da escrita, o que acarreta o problema da escrita nas escolas". ${ }^{\prime}$

Em virtude da deficiência na formação de professores quanto ao ensino da escrita, o livro didático, em alguns casos, torna-se o único suporte para o professor. Desse modo, o docente está sujeito a uma proposta de correção de escrita limitada a procedimentos de correção que podem não corresponder às expectativas de seus alunos.

Como proposta de análise desses procedimentos de correção de escrita que podem sancionar limites ao processo de correção, esta pesquisa tem como tema analisar a grade de correção sugerida pelo Caderno da Cidade de Língua Portuguesa do Município de São Paulo ${ }^{4}$ do ciclo autoral, que corresponde ao sétimo, oitavo e nono anos. Especificamente, visa examinar o eixo "indícios de autoria", indicado como um dos critérios na avaliação da produção escrita dos alunos desse ciclo.

O Caderno da Cidade foi adotado nas escolas municipais da cidade de São Paulo, em meados de março de 2018, com a proposta de atender à BNCC (Base Nacional Comum Curricular), que pretende unificar o ensino regular em todo o Brasil. Diante de novas perspectivas de ensino, esse material tem como meta atender no ensino de língua materna a quatro eixos organizadores: prática de leitura de textos, prática de escuta e produção de textos orais, prática de análise linguística e prática de produção de textos escritos. É a partir do último eixo em que serão baseados os estudos deste trabalho, por meio da grade de correção de texto escrito sugerida.

Desse modo, o objetivo geral deste estudo visa investigar como se organizam os procedimentos de correção propostos pelo Caderno da Cidade, tendo como objetivo específico analisar o eixo "indícios de autoria", investigando como as marcas de subjetividade são consideradas na avaliação de texto escrito. Diante disso, despertam-se as seguintes

3 Colleges and universities simply do not prepare teachers for the teaching of writing, and therein lies the problem with writing in the schools.

4 O Caderno da Cidade faz parte do material didático disponibilizado a professores do ensino fundamental da rede municipal de ensino de São Paulo. Por se tratar de um material cuja consulta apenas está autorizada para o membro docente da respectiva rede, nesta pesquisa não foi possível disponibilizar o material, por não ter autorização prévia de divulgação, contudo, a parte em que consiste o cerne da análise será divulgada para estudo. 
perguntas de pesquisa: estaria essa referência de correção permitindo que o professor avalie de maneira efetiva o texto dos alunos quanto às questões de autoria e subjetividade? Ela estaria oferecendo ao aluno um retorno que melhoraria sua escrita?

Esta pesquisa se justifica, porque salienta a importância de se considerar no processo de correção de texto escrito a subjetividade do aluno, como um indício importante de autoria e de construção do texto. Quando em uma correção padronizada não permite absorver a intencionalidade do redator com a escolha de suas palavras e pensamentos, perde a possibilidade de trabalhar com o texto a partir daquilo que o aluno demonstra como relevante, ou seja, seu posicionamento no mundo.

Teoricamente, a análise foi embasada nas questões do sujeito quanto à linguagem, por meio das teorias de Lacan e Ducrot; das propostas de Riolfi e Magalhães sobre o comportamento do sujeito nas produções escritas e um estudo a partir das proposições a respeito do eixo prática de produção de texto escrito, abordada no Currículo da Cidade do município de São Paulo. Além de tanger as teorias pós-críticas do currículo discutidas por Stephen Ball e Richard Bowe (1992) no chamado Ciclo de Políticas.

Para realizar este trabalho, foi utilizado um corpus composto de minicontos elaborados por alunos pertencentes ao chamado Ciclo Autoral, a partir da grade de correção proposta pelo Caderno da Cidade. Os resultados apontam que determinada grade dá margem a respostas avaliativas dicotômicas por parte do professor: "sim" ou "não". Conclui-se que tal questionamento do material não permite uma avaliação aprofundada da subjetividade e autoria do aluno, abrangendo uma parte superficial dos indícios de autoria e uma conceitualização vaga do que seria subjetividade, podendo trazer um olhar pouco reflexivo no processo de correção.

\section{Pressupostos teóricos}

A formação do Currículo da Cidade de São Paulo

O Brasil passou por vários processos de construção do currículo escolar. Nos anos 80 (período de redemocratização do país), por exemplo, as teorias críticas do currículo passaram a ter grande influência nas construções desses documentos; já nos anos 90, vivenciamos o perío- 
do do multiculturalismo, dos estudos culturais e de gênero, período das teorias então chamadas pós-críticas. Nos anos 2000, o país estava imerso nas teorias pós-estruturalistas, período em que os embates passaram a ter grande importância para os negros e os indígenas.

Nos dias atuais, as teorias sofrem uma forte influência dos organismos multilaterais, como o Banco Mundial, buscando promover competências dirigidas à resolução de problemas imediatos. Isso sob um viés sociológico e intercultural da sociedade, ou seja, com o olhar atento à diversidade (NEIRA, 2018). Vale lembrar que concomitantemente a essas teorias, as teorias tradicionais do currículo sempre estiveram presentes.

O surgimento de uma proposta de reformulação para o currículo da Educação Básica vem ao encontro desses novos conceitos, tendo como prioridade a necessidade de se elevar os índices dos resultados obtidos em avaliações de larga escala, que estão sendo aplicadas, principalmente na rede pública de ensino (GERALDI, 2015). Com o resultado obtido nessas avaliações, emerge a necessidade de também reformular o currículo de novos professores, o que desencadeou a participação de reconhecidos professores universitários, além de pesquisadores e técnicos na formulação da Base Nacional Comum Curricular (BNCC). Em consonância com a BNCC, a Secretaria Municipal de Educação de São Paulo, em 2017, produz o Currículo da Cidade, que segundo o documento:

O Currículo da Cidade busca alinhar as orientações curriculares do Município de São Paulo ao processo de construção da Base Nacional Comum Curricular (BNCC), documento que define as aprendizagens essenciais que todos os estudantes brasileiros têm direito ao longo da Educação Básica. (SÃO PAULO, 2017, p.12)

Quanto ao currículo de Língua Portuguesa, O Currículo da Cidade tem como proposta de trabalho o ensino da linguagem a partir do texto, sendo este considerado como materialidade do discurso, em que a língua se materializa, tornando-se linguagem (SÃO PAULO, 2017). Segundo o documento, para que o uso do texto seja considerado relevante no processo ensino-aprendizagem, faz-se necessário que o repertório trabalhado tenha correspondência direta com o meio social em que o aluno se insere, ressaltando a necessidade de que a "linguagem verbal é uma prática social" (SÃO PAULO, 2017, p. 85). 
Para entender essa proposta de que a linguagem verbal seja uma prática social, o Currículo da Cidade se baseia em quatro eixo organizadores, propostos por Geraldi (2012) e Lerner (2002): prática de leitura de textos; prática de produção de textos escritos; prática de escuta e produção de textos orais e prática de análise linguística. Para esta pesquisa, o enfoque será analisar o eixo prática de produção de textos escritos.

Os procedimentos de correção de texto escrito no Currículo da Cidade

Observando as teorias do currículo, nota-se que desde as teorias tradicionais, principalmente desde Bobbit, houve o questionamento de qual seria a real utilização social do documento. $O$ autor mencionado também cita a necessidade de expor os objetivos educacionais nos currículos com clareza. Essas ideias das teorias tradicionais refletem nas teorias contemporâneas - até porque se sabe que as teorias convivem entre si e não se desmembram inteiramente diante de uma novidade. Com isso, atualmente, olhando para a disciplina de Língua Portuguesa, na correção de redações, há essa necessidade de clareza: o aluno deve saber o que está sendo avaliado, assim tem uma chance de observar seu desenvolvimento intelectual, ou seja, aqui, o currículo já é visto como um instrumento de motivação - logo, tem relevância social.

A produção de texto escrito faz parte do cotidiano dos alunos do ensino básico há bastante tempo, e muitos manuais de propostas de correção já foram utilizados como recurso para os professores na atribuição de uma possível nota nessas produções. Embora esses manuais apontem uma direção para a correção das redações, eles deixam de lado algumas particularidades que possam contribuir na progressão escritora dos alunos, sujeitando os docentes a apenas observarem termos específicos que se distanciam da criatividade e subjetividade do leitor.

É fato que há gêneros em que a subjetividade não deva aparecer e que os alunos precisam conhecer, pois são imersos na sociedade e de algum modo serão produzidos por eles, no intuito de atingir um determinado objetivo. O preenchimento de um formulário de inscrição para um concurso, por exemplo, não trará traços de subjetividade declarada, em virtude de seu caráter estritamente informal.

Contudo, em se tratando de produções narrativas no âmbito do Ensino Fundamental essas marcas de subjetividade ficam evidentes e 
precisam ser consideradas como um indício de singularidade. Partindo desse pressuposto, o docente poderá ser capaz de compreender qual a intenção da produção de um determinado enunciado em um contexto escrito.

De acordo com Ducrot (1987, p. 166) "[...] como fragmento do discurso - o enunciado deve ser distinguido da frase, que é uma construção do linguista, e que permite dar conta dos enunciados". Desse modo, ao avaliar o texto baseando-se apenas na construção da frase pelo viés da estrutura gramatical, desconsidera-se como o discurso produzido foi evidenciado no enunciado e a capacidade criativa do autor.

Cada enunciado caracteriza o seu sujeito, pois a escolha da formação de enunciados vem ao encontro daquilo que o autor considera como relevante e que faz parte de seu contexto social. Para Bakhtin (1992, p. 283), "o enunciado - oral e escrito, primário e secundário, em qualquer esfera de comunicação verbal - é individual, e por isso pode refletir a individualidade de quem fala (ou escreve)." Se o enunciado reflete a individualidade do sujeito, as concepções de autoria acabam por ser demarcadas nesse processo, já que a forma de organizar o discurso caracteriza o seu produtor.

Segundo Faraco e Negri (1998), o conceito de autoria está no posicionamento do autor em relação às vozes que constituem o discurso, ou seja, diante dos diversos discursos que são produzidos, àqueles nos quais o autor se baseia, revela seu posicionamento, caracterizando-o. Essas escolhas acabam por revelar a singularidade do sujeito, pois, conforme Riolfi e Magalhães (2008, p. 98), “Expressar singularidade demanda a coragem de expor a própria diferença em se tratando de escrever um texto"

Para tal clareza avaliativa e desenvolvimento, há a demanda do chamado currículo ativo. Um currículo visto como um percurso e não mais como um documento disciplinador. Diante disso, as grades de correção seriam um passo direcionando essa caminhada a ser feita pelo aluno. Contudo, a noção de grade avaliativa pode acabar sendo fechada em si mesma, se não for olhada criticamente. Há de se valorar os aspectos não gramaticais da correção, para que ela não ganhe um caráter estanque, ou seja, é preciso ter um olhar atento e não automatizado para as produções textuais e para a autoria, especificamente para a subjetividade, para a necessidade de a avaliação de um texto ultrapassar os limites superficiais de correção. 
A subjetividade, quando observada, ultrapassa os limites formais do texto. Ela mostra, além da criatividade dos alunos, suas marcas de autoria. Entretanto, esse olhar crítico necessário muitas vezes é negligenciado pelo professor, que possui uma sobrecarga laboral, e acaba secundarizando a importância da criticidade e de aspectos não formais das redações, o que seria um obstáculo a ser pensado.

Hoje, vivenciando as teorias pós-críticas, um dos conceitos norteadores de currículo foi o de multiculturalismo, em que vários grupos sociais ganharam direito à representação. Assim, com esses percursos curriculares, observa-se que as pessoas dão sentido à realidade, e não estão mais a representando, simplesmente: há a negociação dos sentidos, e a identidade é construída por meio da linguagem também. Com isso, a noção de identidade e de subjetividade teve espaço com o passar das décadas: tem-se a identidade pensada como representante das diferenças, como aquilo que eu quero ser; e a subjetividade, ainda que discretamente destoante da noção de identidade, advém desta: se é nas minhas relações e espaços sociais que crio a minha identidade, nela está refletida a minha subjetividade, que também é marcada pelas diferenças.

Essa visão de identidade das teorias curriculares atuais está calcada nos estudos culturais que são sensíveis às diferenças, logo, há um passo que se afasta do chamado daltonismo cultural, a visão homogeneizadora do professor, para um olhar em gradiente para essas diferenças, assim, volta-se o olhar para a noção de subjetividade, de maneira reforçada pela noção de autoria e isso foi refletido na grade de correção em estudo, embora de forma pouco reflexiva. Além da criatividade, a análise aprofundada da subjetividade mostraria o refinamento da escrita do aluno, sua atividade de agenciamento de texto, indo além do que se espera de uma redação regulada por um avaliador que observa somente se um texto está seguindo determinado gênero textual.

Em detrimento de uma correção em que os valores de autoria e subjetividade fossem considerados no processo de correção de texto escrito, apresenta-se a grade de correção sugerida pelo Caderno da Cidade - Saberes e Aprendizagens do $9^{\circ}$ ano, cujo apontamento sobre os elementos de autoria e subjetividade na produção de minicontos apenas revela questionamentos que não permitem ao professor considerar a autoria e a subjetividade como termos relevantes no processo de correção. 
Quadro 1 - Ficha de avaliação "Miniconto"

\begin{tabular}{|c|c|c|}
\hline \multicolumn{3}{|c|}{ Ficha de Avaliação - Miniconto - Para o(a) professor(a) } \\
\hline EIXO & PONTUAÇĀO & CRITERIOS \\
\hline $\begin{array}{l}\text { Adequaçáo } \\
\text { ao tema }\end{array}$ & & $\begin{array}{l}\text { - O miniconto faz referencia ao tema ou a um dos contos escolhidos pela } \\
\text { turma e foi bem articulado pelo autor? }\end{array}$ \\
\hline \multirow[t]{2}{*}{$\begin{array}{l}\text { Adequaçato } \\
\text { ao Genero }\end{array}$} & & $\begin{array}{l}\text { Aspectos discursivos: } \\
\text { - Há concisáo, isto é, o poder de síntese. Do latim, o significado estaria } \\
\text { próximo à "arte de cortar". } \\
\text { - Contém elemento de narratividade - atividade de narrar ou contar uma } \\
\text { história? } \\
\text { - Está presente a intertextualidade ou, em outras palavras, a relaçăo dire- } \\
\text { ta ou indireta que se estabelece com outros textos? } \\
\text { - Há emprego de linguagem simples, direta e extremamente informal? } \\
\text { - Faz um recorte preciso de um momento que significa muito, mas com } \\
\text { poucas palavras? } \\
\text { - Usa de recursos linguistico-discursivos, tais como paradoxo, ironia e a } \\
\text { sátira? } \\
\text { - Insere novos formatos, nâo-literários, de tecnologia e meios de comu- } \\
\text { nicaçấo modernos? } \\
\text { A linguagem está adequada ao leitor e ao portador em que o miniconto } \\
\text { crculará? }\end{array}$ \\
\hline & & 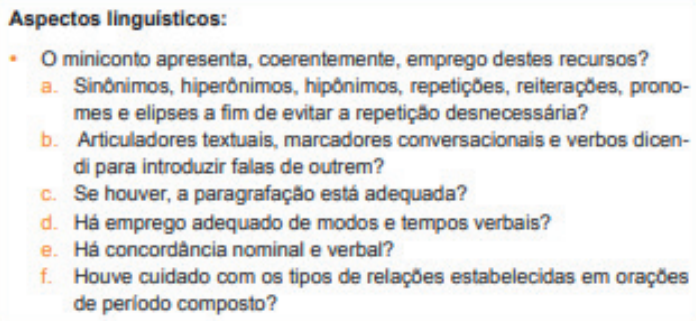 \\
\hline $\begin{array}{l}\text { Indlicios de } \\
\text { Autoria }\end{array}$ & & $\begin{array}{l}\text { - Seleçáo de palavras e expressठdes que ajudam a produzir sentidos } \\
\text { para o texto narrativo? } \\
\text { - O(a) autor(a) expressa um olhar subjetivo, sem deixar de lado o as- } \\
\text { pecto interdiscursivo sobre o tema? } \\
\text { - Há criatividade-a açao de (re)criar algo por meio de outros discursos e textos. }\end{array}$ \\
\hline $\begin{array}{l}\text { Convençoes } \\
\text { da Escrita }\end{array}$ & & $\begin{array}{l}\text { - O miniconto está grafado de acordo com a variedade adotada para } \\
\text { a redaçăo do texto? } \\
\text { - A pontuaçấo está adequada e ajuda na construçăo de sentidos? }\end{array}$ \\
\hline
\end{tabular}

Fonte: Caderno da Cidade - Saberes e Aprendizagens $9^{\circ}$ ano - São Paulo (2018, p.123)

Para efeito de análise, nesta pesquisa, destaca-se examinar minicontos produzidos por alunos do $9^{\circ}$ ano, observando apenas o eixo indícios de autoria sugerido pela ficha de avaliação. Posteriormente, em contrapartida ao que foi sugerido pelo currículo, demonstram-se alguns apontamentos que não foram considerados no processo de avaliação do texto e denotam valores significativos de autoria e subjetividade. 


\section{Análise de dados}

para esta pesquisa, foram selecionadas quatro produções de minicontos com o intuito de analisar o item "indícios de autoria", que pertence à ficha de avaliação proposta pelo Caderno da Cidade do $9^{\circ}$ ano (Quadro 1). A proposta de produção de miniconto, abaixo sugerida, vai ao encontro do que o currículo propõe como atividades suplementares. Estas atividades complementam as que foram praticadas no caderno com o intuito de colaborar com a assimilação do conteúdo.

Proposta de atividade

Escolha um conto de fadas ou uma história que seja bastante conhecida como referência ao seu miniconto. Lembre-se de destacar em seu texto um fato importante da história original para que o seu leitor possa entender a sua proposta.

Para a confecção de seu miniconto, observe as orientações abaixo:

1. Seu texto não precisa ter um título, contudo, se houver, deve fazer referência direta à história;

2. Utilize apenas o espaço limitado para escrever o miniconto;

3. Não se esqueça de que o miniconto é uma narração, portanto, você deve escrever uma história.

No processo de avaliação dos minicontos, o professor usou como base a ficha de correção do caderno, na tentativa de observar as competências que os alunos atingiram na produção do texto. Quando observado o quadro: Indícios de autoria, a proposta de correção apenas exige respostas com o valor de sim ou não. Seguindo esse modelo, o valor da autoria do aluno e de seu valor subjetivo à produção não se torna um objeto de investigação interessante por parte do professor. Observa-se, a partir dos minicontos escolhidos, que a perda de uma análise mais criteriosa dos textos não estimula o professor, a partir dessas produções, a observar o comportamento dos alunos quanto à sua subjetividade, $\mathrm{e}$ por intermédio disso, promover atividades que sejam motivadoras ao estudante.

Na busca de se obter um sentido ao texto, é prudente reconhecer quais os indícios que permeiam o valor significativo do enunciado, já que tanto na fala quanto na escrita a forma que se organiza o enunciado denuncia o que se quer dizer com aquilo. Perante isso, assim como relata 
Ducrot (1987, p.173), "[...] interpretar uma produção linguística consiste, entre outras coisas, em reconhecer nela atos, e que este reconhecimento se faz atribuindo ao enunciado um sentido, que é um conjunto de indicações sobre a enunciação".

As produções selecionadas serão analisadas a partir da proposta feita pelo Caderno da Cidade, observando, como se sugere, avaliar os índices de autoria e subjetividade. Posteriormente, serão discutidos quais valores podem ser agregados ao enunciado escrito quanto a esses mesmos critérios, por uma leitura mais detalhada. Para efeitos de comparação, os textos escolhidos foram criados a partir do Conto de Fadas: Cinderela.

\section{Exemplo 1}

Cinderela então, desesperada, desceu as escadas correndo, mas ao perceber que esqueceu um sapatinho, voltou e pegou, afirmando que "Esse sapato é caro demais".

Resumo: Cinderela vendeu os sapatinhos, com o dinheiro comprou um apartamento, enquanto o príncipe passou o resto de sua vida a procurando. (Erik Rodrigues).

\section{Exemplo 2}

No final descobrimos que na verdade a perda do sapatinho de cristal foi só um truque de Cinderela para conquistar o príncipe. E não é que funcionou mesmo.... (Sara Leal)

Quadro 2 - Guia de correção das redações

\begin{tabular}{|l|c|}
\hline \multicolumn{1}{|c|}{ INDÍCIOS DE AUTORIA } & $\begin{array}{c}\text { POSSÍVEIS } \\
\text { RESPOSTAS }\end{array}$ \\
\hline $\begin{array}{l}\text { Seleção de palavras e expressões que ajudam a produzir } \\
\text { sentidos para um texto narrativo? }\end{array}$ & Sim (x) Não ( ) \\
\hline $\begin{array}{l}\text { O (a) autor (a) expressa um olhar subjetivo, sem deixar de } \\
\text { lado o aspecto interdiscursivo sobre o tema? }\end{array}$ & Sim (x) Não ( ) \\
\hline $\begin{array}{l}\text { Há criatividade - a ação de (re) criar algo por meio de } \\
\text { outros discursos e textos? }\end{array}$ & Sim (x) Não ( ) \\
\hline
\end{tabular}

Fonte: Elaborada pelos autores 
As marcas dos autores, no exemplo 1 e 2 , pressupõem a presença de vozes que transpassam apenas a história da Cinderela, assim como defendido por Ducrot, o enunciado está repleto de outras vozes que compõem o sentido do texto e que autor nomeia de polifonia. No exemplo 1, o aluno inicia o texto em consonância com a história já conhecida, contudo, ele traz um comportamento diferente ao que é atribuído à personagem. Pode-se notar a presença de um valor cômico ao texto, sugerindo que Cinderela estava mais interessada no valor do sapato do que realmente conquistar um príncipe encantado, enquanto no exemplo 2, a autora põe em xeque a ingenuidade da personagem, revelando que a perda do sapatinho tinha sido uma estratégia nada inocente de conquistar o príncipe.

O que torna os textos singulares, diante do conto-de-fada conhecido, é o desprendimento do viés romântico proposto pelo conto, valendo-se em abordar um comportamento da personagem voltado à ambição, independência financeira e o caráter duvidoso da Cinderela. Isso se justifica, por intermédio das teorias de Lacan (1996) quanto à submissão do sujeito ao significante. Nesse caso, o autores se incluem na operação de separação - em que o sujeito se afasta de um significante qualquer - fugindo de um estereótipo da personagem apresentado pelo enredo original.

\section{Exemplo 3}

Maquiagem, cabelo e vestido prontos. Agora só preciso deixar meu sapatinho de cristal no castelo e esperar o príncipe apaixonar-se e me tirar dessa casa horrível. (Cecília Aparecida Souza Lima)

\section{Exemplo 4}

-Ah, se fosse comigo, eu logo diria para a fada madrinha:

-Ei, não quero ir ao baile coisa nenhuma, posso fazer outro pedido?

-Claro, sou a sua fada madrinha., O que desejas?

-Um carro, uma casa, um iphone, uma bicicleta e uma nota 10 para esse miniconto maravilhoso. Fechado?

- Seu desejo é uma ordem. Kabrummmmmmm (Luis Fernando de Carvalho Pinheiro) 
Quadro 3 - Guia de correção das redações

\begin{tabular}{|l|c|}
\hline \multicolumn{1}{|c|}{ INDÍCIOS DE AUTORIA } & $\begin{array}{c}\text { POSSÍVEIS } \\
\text { RESPOSTAS }\end{array}$ \\
\hline $\begin{array}{l}\text { Seleção de palavras e expressões que ajudam a produzir } \\
\text { sentidos para um texto narrativo? }\end{array}$ & $\operatorname{Sim}(\mathrm{x})$ Não ( ) \\
\hline $\begin{array}{l}\text { O (a) autor (a) expressa um olhar subjetivo, sem deixar de } \\
\text { lado o aspecto interdiscursivo sobre o tema? }\end{array}$ & $\operatorname{Sim}(\mathrm{x})$ Não ( ) \\
\hline $\begin{array}{l}\text { Há criatividade - a ação de (re) criar algo por meio de } \\
\text { outros discursos e textos? }\end{array}$ & $\operatorname{Sim}(\mathrm{x})$ Não ( ) \\
\hline
\end{tabular}

Fonte: Elaborado pelos autores

Nos exemplos 3 e 4, despertam marcas de singularidade por meio da escolha do próprio foco narrativo. Os autores se valem da $1^{\text {a }}$ pessoa, retratando o enredo sob o olhar de Cinderela, o que não acontece na versão original. No exemplo 3, a autora, assim como no exemplo 2 , retrata que a personagem não estava interessada apenas no príncipe, mas naquilo que ele poderia oferecer "[...] me tirar dessa casa horrível".

Os minicontos esperam que seus leitores não sejam apenas conduzidos ao olhar estritamente conhecido da história, mas se estranhem com o desfecho e percebam as marcas de singularidade e autoria nesse novo contexto. Esse estranhamento do leitor, de acordo com Riolfi e Magalhães (2008), podem sancionar dois comportamentos: o primeiro, observar que o significante não atende à priori o significado do texto de origem, promovendo dessa forma um novo olhar sobre o texto e o segundo, retroagir sobre o dizer para alcançar o objetivo, valendo do teor criativo do autor para compreender sua ideia.

No exemplo 4, vale ressaltar a dinâmica do autor em cumprir o papel proposto pela atividade, valendo-se principalmente do humor. As marcas da subjetividade do texto ficam evidentes quando o autor retrata o que de fato considera como relevante a ser pedido a uma fada madrinha: nada de príncipe, o interesse por bens materiais e uma boa nota com o seu texto são mais significativos. Consoante Riolfi e Magalhães (2008), pode-se considerar que o aluno está em uma posição subjetiva nomeada como Sujeito agenciado pelo aluno a partir do cotejamento das demandas da cultura escolar e de uma ética própria, em que o texto produzido por meio da obrigação de se escrever uma 
atividade escolar é permeado por uma construção que identifica marcas explícitas de singularidade.

Os exemplos apresentados discorrem à necessidade de um olhar reflexivo quanto à subjetividade do sujeito no processo de escrita. Assim como menciona Amatuzzi (2006, p. 94), "Subjetividade é o abstrato do sujeito". Desse modo, no ato de escrever, o aluno está aquém de uma escrita totalmente comprometida em realizar uma tarefa, mas poderá, por sua vez, demonstrar indícios de subjetividade que podem caracterizá-lo em seu processo de construção textual. Em uma atividade em que o professor consegue inferir esses indícios tão importantes para identificar a singularidade do texto, pode-se encontrar meios de se trabalhar a escrita com um objetivo muito mais crítico do que aquele exposto, aqui, pela grade de correção. O miniconto como objeto para identificação da subjetividade se torna um instrumento enriquecedor nesse processo, já que sua estrutura permite que em poucas palavras o professor consiga observar tais marcas mais rapidamente.

\section{Considerações finais}

O desenvolvimento deste estudo possibilitou uma análise de como as grades de correção oferecidas pelo Caderno da Cidade - Volume 1, ainda que contendo um espaço dirigido para tais conceitos, não se aprofundam na questão da autoria e da subjetividade dos alunos. A presença de determinado quadro de correção que trata desse assunto parece ser um grande ganho no ensino de escrita nas escolas municipais de ensino. Com a grade, o professor tem um método para guiar sua correção, método este que olha para as identidades dos alunos - ou pelo menos tentam - como prevê os currículos embasados no multiculturalismo contemporâneo.

Contudo, esse olhar se inclina para um mero formalismo escolar: os conceitos citados seriam mais um ponto a ser cumprido pelo aluno no momento de sua produção textual, visto que sua nota dependerá do cumprimento de tal categoria da grade, no caso, o quadro denominado de autoria. Se na correção o professor considerar que a escrita avaliada é autoral, com marcas subjetivas, pontos a mais serão atribuídos à redação e esse seguimento da grade torna-se secundário. Seria interessante para possíveis análises futuras observar se no preparo do aluno para a produção escrita o professor trabalhe em suas aulas a noção de autoria 
e subjetividade, instigando os alunos a observarem a si mesmos e suas criações, como autores de seu próprio texto, e não apenas se pautando em referências dadas pelo professor.

\section{Referências}

AMATUZZI, M.M. A subjetividade e sua pesquisa. Memorandum, Belo Horizonte, v.10, p.93-97, 2006.

BAKHTIN, M. Estética da criação verbal. São Paulo: Martins Fontes, 1992.

BALL, S.J.; BOWE, R. Subject departments and the "implementation" of National Curriculum policy: an overview of the issues. Journal of Curriculum Studies, London, v. 24, n. 2, p. 97-115, 1992.

DUCROT, O. O dizer e o dito. Campinas: Pontes, 1987.

FARACO, C. A.; NEGRI, L. O falante: que bicho é esse, afinal? Revista Letras, Curitiba, n. 49, p. 159-170, 1998.

GERALDI, J. W. (Org). $O$ texto na sala de aula. São Paulo, Anglo, 2012.

GERALDI, J. W. (Org). O ensino de língua portuguesa e a Base Nacional Comum Curricular. Revista Retratos da Escola, Brasília, v.9, n.17, p.381396, jul./dez. 2015.

HILLOCKS, JR. G. Research in writing, secondary school, 1984-2003. L1 Educacional Studies in Language and Literature, n. 6, p. 29-52, 2006.

LACAN, J. Subversão do sujeito e dialética do desejo freudiano [The Subversion of the subject and the Dialectic of Desire in the Freudian Unconscious]. in: LACAN, J. Escritos. São Paulo: Perspectiva, 4.ed., p. 275311.1996.

LERNER, D. Ler e escrever na escola: o real, o possível e o necessário. Porto Alegre: Artmed, 2002.

NEIRA, M. G. Teorias do Currículo - Aula 08 - As teorias pós-críticas. 2018. 1 video (20m54s). Publicado pelo canal UNIVESP. Disponível em: https://www.youtube.com/watch?time_continue $=4 \& v=M q B q y l Y a T 2 k$. Acesso em: 31 out. 2018.

RIOLFI, C. R.; MAGALHÃES, M.M.M. Modalizações nas posições subjetivas durante $o$ ato de escrever. Estilos da Clínica, v.13. n. 24, p. 98-121, 2008. 
SÃO PAULO (SP). Secretaria Municipal de Educação. Coordenadoria Pedagógica. Currículo da Cidade: Ensino Fundamental: Língua Portuguesa. São Paulo: SME/COPED, 2017. Disponível em: https://www. sinesp.org.br/images/2017/BaseCurricular-2018-Portugues.pdf. Acesso em: 24 de nov. 2018.

SÃO PAULO (SP). Secretaria Municipal de Educação. Coordenadoria Pedagógica. Caderno da cidade: saberes e aprendizagens : Língua Portuguesa - livro do(a) professor(a) - $9^{\circ}$ ano - v 1. - São Paulo: SME / COPED, 2018.

Recebido: Novembro/ 2018

Aceito em: Janeiro/ 2019 